\title{
A Relação entre a Redução das Ocupaçōes de Terra e as Mudanças no Confronto em torno da Reforma Agrária no Brasil
}

The Relation Between the Reduction of Land Occupations and the Changes in Confrontation over Agrarian Reform in Brazil

Ramon Torres Araujo ${ }^{1}$

Recebido em 16/01/2016 e aceito em 01/04/2016.

Resumo: Este trabalho tem como objetivo compreender a redução das ocupações de terra no Brasil. Na década de 1990, houve uma tendência à intensificação das ocupações, que alcançou seu ápice em 1999, quando foram realizadas 856 ações. Mas a partir de 2005 esta tendência se inverteu, atingindo a marca de 116 ocupações em 2010. Verificou-se que este fenômeno está relacionado a quatro condições sociais que expressam as mudanças no confronto em torno da reforma agrária: a mudança na orientação política da organização que mais empregou este repertório; a emergência de governos que não reconhecem a ocupação enquanto um repertório legítimo; a diminuição de um contingente de pessoas dispostas a se engajar nas ocupações; o arrefecimento do apoio de diversos atores relevantes à bandeira da reforma agrária.

1 Mestre em Sociologia pelo Instituto de Estudos Sociais e Políticos da Universidade do Estado do Rio de Janeiro (IESP-UERJ) e atualmente cursa o doutorado na mesma Instituição. E-mail: ramontorresaraujo@gmail.com 
Palavras-chave: Ocupação de terra; repertório de ação; reforma agrária; confronto político.

Abstract: This work has as objective to understanding the reduction of land occupations in Brazil. In the decade 1990's, there was a trend to increase the number of occupations, reaching the peak in 1999, when there were 856 occupations. But from 2005 this trendhas reversed, reaching the mark of 116 actions in 2010. It was found that this phenomenon is related to four social conditions that express the changes in the confrontation over agrarian reform: the change in the political orientation of the organization that mostly employed this repertoire; the emergence of governments that do not recognize the occupation as a legitimate repertoire; the reduction of a contingent ofpeople to engage in these actions; the weakening of the support of relevant actors to the agrarian reform banner.

Keywords: Land occupation; repertoire of action; agrarian reform; contentious politics.

\section{INTRODUÇÃO}

As ocupações de terra compõem o repertório de ação dos movimentos sociais que vêm reivindicando a profunda transformação da estrutura fundiária brasileira desde o início dos anos 1960. Com a intensificação da repressão, após o golpe de 1964, esta forma de ação foi solapada, voltando a ser empregada apenas no final dos anos 1970. Nas décadas de 1980 e 1990, a ocupação se estabeleceu como a principal forma de reivindicar a desapropriação e redistribuição das terras no confronto político em torno da reforma agrária ${ }^{2}$. Segundo o

2 Importante frisar que esse trabalho tratará das ocupações de terra que estão relacionadas ao confronto político em torno da reforma agrária, pois existe uma série de grupos indígenas e quilombolas que também empregam ocupações como meio de reivindicar a desapropriação e redistribuição das terras, mas que não estão envolvidos nesse tipo de confronto. Apesar de todas essas ocupações terem como um dos principais objetivos a conquista da terra, há pontos fundamentais que são diferentes, como, por exemplo, os 
Banco de Dados de Luta Pela Terra (DATALUTA) ${ }^{3}$, apenas na década de 1990 foram empreendidas mais de três mil ocupações em diferentes regiões do país. No entanto, a partir da segunda metade da década de 2000, o número de ocupações de terra começou a diminuir consideravelmente. Depois de atingir o ápice de 856 ocupações apenas no ano de 1999, em 2010, foram registradas 166 ações deste tipo, ou seja, 690 a menos do que no ano de 1999 (ver Gráfico 1) ${ }^{4}$.

O presente artigo tem como objetivo analisar esse fenômeno, buscando compreender o porquê da principal forma de se reivindicar uma reforma agrária distributivista, empregada com tamanha intensidade durante a década de 1990, entrar numa tendência decrescente e passar a ser empregada com uma frequência muito menor.

A pesquisa fundamentou-se em dados extraídos de matérias, entrevistas e documentos publicados em diferentes meios, além de dados quantitativos que foram importantes para se estabelecer uma dimensão nacional de análise. Também lancei mão de trabalhos que se propuseram a estudar casos específicos de ocupações para compreender as características mais gerais desse repertório de ação. Não busquei, portanto, revelar novas informações sobre aspectos específicos relacionados às ocupações de terra, mas formular explicações relacionadas às regularidades comuns às diversas ocupações específicas.

atores envolvidos no confronto, as relações que os desafiantes possuem com a terra e os argumentos empregados para legitimar as suas ações.

3 Para se ter acesso aos dados elaborados pelo DATALUTA, é necessário realizar um pedido formal ao Núcleo de Estudos, Pesquisas e Projetos de Reforma Agrária da Universidade Estadual Paulista (NERA-UNESP).

4 Interessante notar que, ao mesmo tempo em que as ocupações relacionadas ao confronto em torno da reforma agrária diminuíram consideravelmente, as ocupações realizadas por grupos indígenas e quilombolas aumentaram. Segundo o DATALUTA, enquanto que em 2003 foram registradas cinco ocupações realizadas por grupos indígenas e quilombolas, em 2012, o número de ocupações realizadas por esses grupos subiu para 49, oferecendo indícios de que está havendo mudanças na luta pela terra. 
Grafico 1 - Brasil - Número de Ocupações - 1988-2012

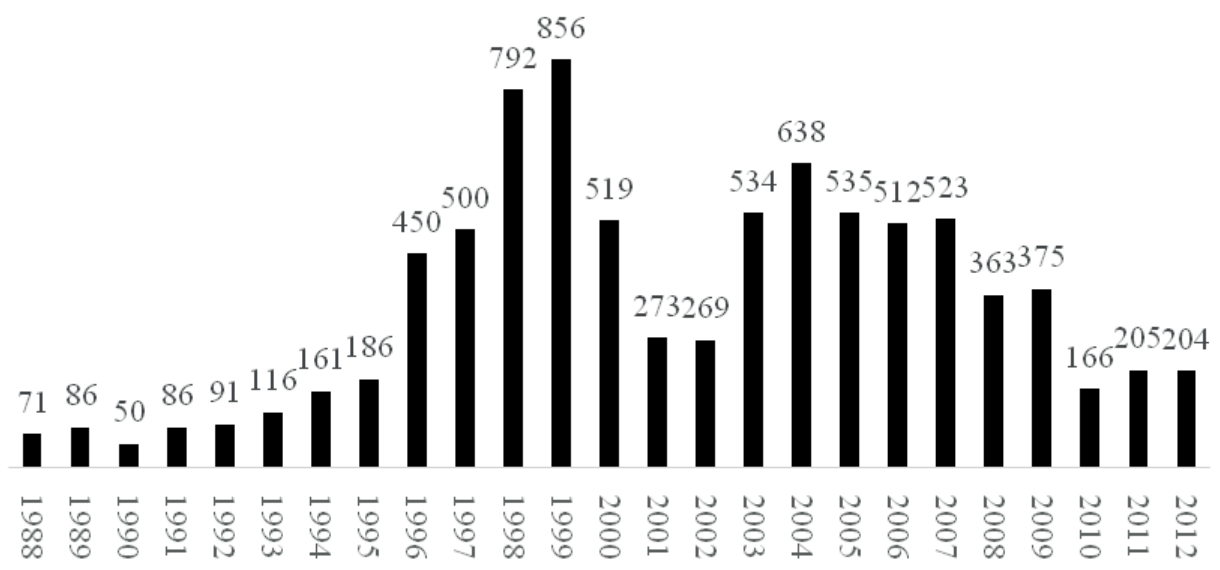

Fonte: Elaboração própria a partir dos dados do Banco de Dados da Luta pela Terra - DATALUTA.

A despeito das diversas ocupações comportarem variações ao longo do tempo e das localidades em que foram empregadas (MACEDO, 2005), creio que seja possível realizar inferências mais gerais a partir dos casos específicos que foram tratados nas chamadas fontes secundárias. A compartimentalização dos estudos sobre os movimentos sociais no país se acompanha, em geral, de uma tendência muito empiricista que se, por um lado, ajuda a desvelar informações fundamentais sobre casos e localidades concretas, por outro, não permite gerar interpretações mais abrangentes.

Na primeira parte do artigo, buscarei expor algumas das características gerais desse repertório de ação. Na segunda parte, apresentarei quatro condições sociais que foram fundamentais para constituição (no pré-64) e reconstituição (no período de redemocratização) das ocupações de terra, assim como para sua disseminação pelo país. $\mathrm{Na}$ terceira,procurarei demonstrar que certas mudanças que ocorreram no confronto em torno da reforma agrária nos últimos anos acabaram prejudicando a existência destas condições e, consequentemente, obstaculizando o emprego das ocupações de terra no Brasil. 


\section{AS OCUPAÇÕES DE TERRA COMO REPERTÓRIO DE AÇÃO}

As ocupações de terra são empregadas no Brasil desde, pelo menos, os anos de 1960, o que pode ser notado nas páginas do jornal Terra Livre ${ }^{5}$. Numa pesquisa realizada nas edições do periódico, publicadas entre os anos de 1954 e 1964, pude encontrar dez casos distintos de ocupações e 17 matérias a respeito. Esse repertório apareceu pela primeira vez nas páginas do jornal numa matéria sobre a luta pela terra na Itália ( $T L$, janeiro de 1956: 2). Segundo a matéria, no dia 19 de outubro de 1955, os camponeses de Sezze Romano ocuparam uma fazenda de 320 hectares para pressionar o governo a cumprir a lei que determinava a desapropriação e redistribuição das terras improdutivas.

É difícil saber se essa notícia influenciou o surgimento das ocupações no Brasil, mas, pelo menos, ela demonstra que existia uma preocupação da equipe do Terra Livre, composta por militantes do PCB que possuíam grande inserção no movimento camponês, em divulgar esse repertório de ação. Além disso, ela expõe um aspecto importante para compreender a luta na qual se inserem as ocupações de terra no Brasil. Assim como na Itália, os grupos brasileiros que adotaram as ocupações como meio de reivindicar a reforma agrária passaram a utilizar como uma das principais justificativas para legitimar as suas ações o argumento de que as terras improdutivas deveriam ser redistribuídas para aqueles que nelas quisessem trabalhar.

As ocupações não são simplesmente aglutinações de indivíduos interessados em obter terra; elas seguem um padrão de ação que pode ser compreendido como uma performance (TILLY, 2006; TARROW, 2011). Primeiro, elassão, na maioria das vezes, promovidas por organizações, como o Movimento dos Trabalhadores Rurais Sem Terra (MST), a Comissão Pastoral da Terra (CPT), a Confederação Nacional

5 O periódico Terra Livre, veiculado entre os anos de 1949-1964,era o órgão do Partido Comunista Brasileiro (PCB) voltado ao público do campo. Para mais informações sobre o jornal, ver Medeiros (1995). 
dos Trabalhadores da Agricultura (CONTAG), entre outras, que mobilizam uma série de indivíduos para entrar numa terra, nela montar acampamento e reivindicar sua desapropriação e redistribuição ao Estado, detentor do monopólio da desapropriação e redistribuição legal das terras (SIGAUD, 2000).

Os acampamentos também seguem certo padrão de organização espacial, geralmente, com suas barracas alinhadas de modo a formar vias internas. Neles, existem regras específicas, um vocabulário próprio euma divisão do trabalho em comissões - o que pode ser visto no documentário Zé Pureza, que trata do processo de formação do acampamento também chamado de Zé Pureza ${ }^{6}$, no estado do Rio de Janeiro. Além disso, há uma série de elementos dotados de forte simbolismo, como a bandeira da organização que é hasteada em frente à ocupação e a lona preta que cobre as barracas. Esse padrão constitui uma linguagem que busca fazer afirmações por meio de ações públicas com o intuito de ser reconhecida e legitimada por diferentes interlocutores. Os diversos atores que se engajam nas ocupações, os defensores da grande concentração fundiária, os governos e o público reconhecem o significado desse repertório de ação. No momento em que os indivíduos adentram numa grande propriedade rural, montam acampamento e reivindicam a sua desapropriação e redistribuição, coloca-se em questão o fim do latifúndio. Assim, todos os envolvidos diretamente no confronto político, compreendendo o que está em jogo, começam a agir para fazer valer seus interesses (MACEDO; ROSA; SIGAUD, 2008).

O Estado, ou melhor, os diferentes atores que agem em seu nome a partir de relações de conflito ${ }^{7}$ podem ou não legitimar as ocupa-

6 ZÉ PUREZA. Direção de Marcelo Ernandez Macedo. Rio de Janeiro, 2006 (97 min.). Disponível em https://www.youtube.com/watch?v=EH4Uf9dSLTw. Acesso em 29 jan. 2015 (33:53 min. $-35: 50 \mathrm{~min}$.).

7 Uma situação interessante que ilustra essa relação de conflito entre diferentes atores que representam o Estado pode ser vista no caso da ocupação da região açucareira do Imbé, situada no município de Campos dos Goytacazes-RJ, no início de 1963. Após os desempregados das usinas de cana-de-açúcar da região ocuparem as terras com a ajuda da Federação das Associações de Lavradores do Estado do Rio de Janeiro (FALERJ), o governador do estado, Badger da Silveira, promoveu uma intensa repressão aos ocupantes, que receberam apoio de sindicatos e do governo de João Goulart (MACEDO, 2010). 
ções. Marcelo Rosa (2004) mostra, em seu artigo, como que a legitimidade conferida por estes atores às ocupações é fundamental para tornar o repertório eficaz. Quando os governos são repressores, de modo a aumentar o custo de mobilização, os atores que se engajam nas ocupações se deparam com uma enorme dificuldade em tornar este repertório eficaz, impedindo, com isso, que a ocupação seja empregada com regularidade e seja reproduzida ao longo do tempo (TILLY, 1978: 155).

\section{AS CONDIÇÕES SOCIAIS DE (RE) CONSTITUIÇÃO E DISSEMINAÇÃO DAS OCUPAÇÕES DE TERRA}

As ocupações de terra se constituíram e se disseminaram em dois períodos da história do Brasil: o primeiro foi do início dos anos 1960 até o golpe de 1964 e o segundo foi do final dos anos de 1970, durante o processo de redemocratização, até o final dos anos 1990. Nesses dois períodos, havia algumas condições sociais que contribuíram para que as ocupações de terra se constituíssem (ou reconstituíssem) e se multiplicassem.

Tanto no período pré-1964, quanto no período pós-regime militar, a bandeira da reforma agrária serviu para formar uma unidade entre os diversos atores que possuíam reivindicações que tinham como eixo central a transformação da posse e do uso da terra (FERREIRA, 2013: 13; MEDEIROS, 1989: 32). Mas não era qualquer concepção de reforma agrária. Nesses dois períodos, as concepções de reforma agrária que norteavam as orientações políticas desses atorem possuíam traços comuns. Primeiro, tinham como principal objetivo promover a profunda transformação da estrutura fundiária, de modo a democratizar o acesso à terra para quem nela quisesse trabalhar. Segundo, só seriam realizadas a partir da ação direta dos sem-terra ou dos com pouca terra. Terceiro, o Estado, por ser o detentor do monopólio da desapropriação e redistribuição legal das terras, deveria participar ativamente da efetivação da reforma agrária - mostrando, como afirmou José de 
Souza Martins, que a luta pela reforma agrária no Brasil sempre foi marcada por intenso legalismo (MARTINS, 2011) ${ }^{8}$.

Nesses dois períodos, também existiam oportunidades políticas (TARROW, 2011: 160) que favoreceram a realização desse repertório de ação. Isto ocorreu, sobretudo, porque se formaram dentro dos governos estaduais e federais grupos que defendiam a bandeira da reforma agrária. Estes governos, além de participarem ativamente da mobilização de indivíduos para promover ocupações, como nos casos dos governos de Leonel Brizola, tanto no Rio Grande do Sul, quanto no Rio de Janeiro, eles legitimavam as ações redistribuindo as terras que eram ocupadas. A atuação de autoridades políticas que atuavam em diferentes instituições estatais, foram decisivas para que diversos casos de conflito pendessem para os interesses dos acampados. Quando esses governos desapropriavam e redistribuíam terras, conferia-se legitimidade à ocupação, que passava a ser vista pelas pessoas como um repertório de ação eficaz. À medida que as notícias sobre as desapropriações iam se espalhando, mais pessoas iam se incorporando às ações e mais ocupações iam surgindo, deixando claro que os diferentes atores avaliavam, segundo suas expectativas, que, naquele ambiente, o investimento necessário para se conquistar um pedaço de terra por meio das ocupações valia a pena.

Como apontou Lygia Sigaud, baseando-se em relatos colhidos no trabalho de campo realizado na Zona da Mata Pernambucana na década de 1990:

Alguns dos que participaram daquela ocupação [em Rio Formoso] contam que no início poucos iam às reuniões preparatórias. Desconfiavam do que lhes era dito e temiam o que pudesse vir a lhes acontecer. Progressivamente o grupo foi aumentando [...] Quando, a partir de 1993, o INCRA começou a desapropriar terras ocupadas, a crença ganhou força e solidez e as pessoas passaram a ter menos medo e menos dúvidas a respeito da pertinência de entrar nas terras dos patrões (SIGAUD, 2004: 18).

8 Para saber mais sobre as diferentes concepções de reforma agrária, ver Medeiros (1982). 
Mas quando governos repressores estiveram à frente do processo, como no caso da ocupação emblemática de Encruzilhada Natalino, realizada no Rio Grande do Sul no período de redemocratização (ROSA, 2010), o apoio de outros atores às organizações de lutas pela reforma agrária foi determinante. Nesse caso, os governos estadual e federal não estavam dispostos a atender as demandas dos acampados.

Chegou a haver uma intervenção ainda mais repressiva do governo federal, que enviou para reprimir o acampamento o, na época, conhecido Coronel Curió ${ }^{2}$. Se não fosse o apoio da Igreja Católica, através de entidades como a Conferência Nacional dos Bispos do Brasil (CNBB), os acampados não sairiam vitoriosos. O fato da Igreja se posicionar a favor dos acampados demonstrou, inclusive, como existiam fissuras dentro do regime militar, que disponibilizaram aliados poderosos (como o alto clero da Igreja Católica) e diminuíram a capacidade repressora do Estado, abrindo um ciclo de oportunidades políticas, como foi ressaltado acima.

Por fim, nos dois períodos, a situação de penúria causada, por um lado, pelas transformações das relações no campo que expulsavam ${ }^{10}$ os camponeses de suas áreas de trabalho e moradia, e, por outro, pela falta de oportunidades para a reprodução social dos trabalhadores nas cidades, gerava um contingente de indivíduos dispostos a se engajar nas ocupações. No caso do Imbé, o grupo que participou da ocupação encontrava-se desempregado e, ainda por cima, estava sendo expulso pelos usineiros das terras onde morava e trabalhava. Além disso, a chegada ao Rio de Janeiro de famílias oriundas dos estados do Espírito Santo e de Minas Gerais, vítima de secas e da falência de núcleos cafeeiros nessas regiões, contribuiu para o processo de mobilização na área rural (MACEDO, 2010: 184).

9 O major Sebastião de Moura, mais conhecido como coronel Curió, fazia parte do serviço de inteligência do Exército e era considerado um especialista em conflitos rurais.

10 Para saber mais sobre o assunto, ver Palmeira (1989). 


\section{AS MUDANÇAS NO CONFRONTO EM TORNO DA REFORMA AGRÁRIA E A REDUÇÃO DAS OCUPAÇÕES DE TERRA}

\subsection{DA REFORMA AGRÁRIA CLÁSSICA À REFORMA AGRÁRIA POPULAR}

O MST foi a organização que mais promoveu ocupações de terra no período pós-regime militar, respondendo por 3.844 ações (45\% do total), o que demonstra a sua importância para a popularização e disseminação deste repertório. É interessante notar que a popularização do próprio MST está estreitamente ligada à quantidade de ocupações que ele realizou, sobretudo, na segunda metade dos anos 1990. O número de editoriais de alguns dos maiores jornais do país (Folha de São Paulo, O Estado de S. Paulo, Jornal do Brasil e O Globo) dedicados ao Movimento acompanhou o número de ocupações de terra (COMPARATO, 2001: 110).

É claro que outros acontecimentos também contribuíram para a popularização do Movimento, como, por exemplo, o Massacre de Corumbiara, em agosto de 1995, o Massacre de Eldorado dos Carajás, em abril de 1996, e a Marcha a Brasília, em 1997. Entretanto, os dois massacres aconteceram em resposta às ações dos sem-terra, e a marcha em resposta aos massacres, ou seja, se o MST não tivesse intensificado as ocupações, provavelmente ele não experimentaria a repressão brutal do Estado em articulação com agentes privados. Portanto, para compreender as dinâmicas das ocupações é necessário compreender, entre outras condições, as orientações políticas desta organização.

Ao longo de duas décadas (1984-2004), o MST estabeleceu o latifúndio como o principal problema a ser enfrentado no campo. Este representava o monopólio e a subutilização da terra e de outros recursos, como a água (JTST, abril de 1988: 12); simbolizava a violência perpetrada contra trabalhadores, agentes pastorais, advogados e lideranças sindicais que se posicionavam a favor da 
reforma agrária (JTST, junho de 1986: 7); significava a injustiça e a imoralidade por impor aos trabalhadores rurais a impossibilidade de usufruir da terra para dela retirar o próprio sustento (JTST, maio de 1988: 14). Portanto, o latifúndio - sempre relacionado à improdutividade - deveria ser o foco das ocupações, das desapropriações e redistribuições (SILVA, 2013: 102).

No seu III Congresso, realizado em Brasília, entre os dias 24 e 27 de julho de 1995, com a participação de mais de cinco mil delegados advindos de 22 estados, a transformação profunda da estrutura fundiária foi reafirmada como objetivo principal. No último dia do Congresso, 28 militantes do MST participaram de uma audiência com o presidente Fernando Henrique Cardoso, que aceitou recebê-los. Dos 42 pontos que constavam na carta de reivindicações, o primeiro era "Desapropriar os maiores latifúndios de cada estado"; o segundo era "Cobrar em terras as dívidas dos latifundiários e usineiros que tem aval do tesouro, destinando-as para a Reforma Agrária”; e o terceiro era "Cobrar imediatamente em terras, as dívidas dos 1.276 maiores devedores inadimplentes do Bando do Brasil e destinar estas terras para Reforma Agrária" (JTST, agosto de 1995: 5). Ou seja, as principais reivindicações (continuando assim até o décimo ponto) diziam respeito à desapropriação e redistribuição das grandes propriedades rurais.

No IV Congresso, realizado em agosto de 2000 , com a participação de aproximadamente 11 mil delegados e autoridades políticas, vindos de 23 estados, fica claro que a profunda transformação da estrutura fundiária era o principal objetivo do MST já na palavra de ordem: "Reforma Agrária: por um Brasil sem latifúndio". Outros documentos do Movimento, como a cartilha elaborada para o Congresso, também apontavam a mudança da estrutura fundiária brasileira como o objetivo que deveria ser priorizado. A primeira questão abordada na cartilha era "A luta contra o monopólio da terra no Brasil" (JTST, julho de 2000: 10). No entanto, o foco na questão fundiária não significou uma abdicação a outras pautas, como a luta por direitos à comida, educação, saúde, cultura, informação, entre outros. O MST foi ao longo dos anos incorporando outras agendas nacionais e internacionais - processo que Breno Bringel (2014) chamou de demandas aglutinadoras. A partir 
da segunda metade dos anos 1990, o Movimento, em consonância com o ciclo de mobilizações "antiglobalização" que irrompeu no cenário mundial, intensificou suas ações contra o chamado "modelo neoliberal" (JTST, fevereiro de 2001: 1).

Entretanto, foi por volta de 2004 que a pauta do MST começou a mudar consideravelmente, com a redefinição do principal problema a ser enfrentado e dos adversários a serem combatidos. O principal problema deixou a ser o monopólio da terra, representado pela figura do latifúndio, e passou a ser o modelo agrícola chamado de agronegócio. As multinacionais, como a Monsanto, Bunge, Cargill, além de outras se transformaram nos principais adversários do Movimento (BRINGEL, 2014). Nesta nova configuração, a disputa fundamental deixou de ser entre aqueles que defendiam uma reforma agrária distributivista e os que defendiam a conservação da estrutura fundiária brasileira, e passou a ser entre os defensores de um novo modelo agrícola (representado pela agricultura camponesa) e os defensores da conservação do modelo hegemônico (representado pelo agronegócio).

No VI Congresso, realizado em fevereiro de 2014, com a participação de aproximadamente 14 mil delegados, esta nova orientação se consolidou, com o lançamento da Reforma Agrária Popular. Neste encontro, a transformação do modelo agrícola foi reafirmada como o principal objetivo. Na carta publicada antes do Congresso para apresentar as novas propostas, a necessidade "de alteração da atual estrutura de organização da produção e da relação do ser humano e natureza" aparece como questão central. A transformação da estrutura fundiária é mencionada apenas como uma medida necessária para se alcançar os objetivos gerais, deixando, portanto, de ser prioritária (MST, 2009).

Para João Paulo Rodrigues e João Pedro Stédile, principais lideranças do MST, a mudança do objetivo foi necessária por causada impossibilidade de haver um grande processo de distribuição de terra dentro da nova fase do capitalismo, dirigido pelo capital financeiro e responsável pela implementação do modelo do agronegócio no campo (RODRIGUES, 2014; STÉDILE, 2014b). Para Gerson Teixeira, presidente da Associação Brasileira de Reforma Agrária (ABRA) e militante do Partido dos Trabalhadores (PT), a mudança ocorreu por causa da relação de aliança entre MST e 
PT. Segundo ele, o Movimento estaria reposicionando o nível das lutas pela terra para evitar conflitos com o governo encabeçado pelo PT, mas composto "por forças muito conservadoras". O PT, por sua vez, temeroso em prejudicar a governabilidade, estaria sendo pouco diligente com a questão da democratização da terra (TEIXEIRA, 2014).

Mas, independente dos motivos que causaram as mudanças nas orientações do Movimento, pode-se afirmar que tais mudanças influenciaram na alteração do repertório, pois, segundo o próprio Stédile, a "forma de luta, de ocupar terras, de fazer machas, era apropriada para enfrentar e derrotar o latifúndio. Era suficiente como tática de luta para conquistar a terra" (STÉDILE, 2014a). Na avaliação dos atores, a democratização do acesso à terra, que era o principal objetivo, deixou de ser adequado ao ambiente político, gerando, assim, a necessidade de se alterar o meio para alcançar o novo objetivo de transformar o modelo agrícola para combater o agronegócio.

\subsection{A HEGEMONIA DO AGRONEGÓCIO E O FIM DO CICLO DE OPORTUNIDADES POLITIICAS}

Em 1999 uma crise de liquidez internacional afetou a economia brasileira, provocando enorme fuga de capitais e forçando a mudança do regime cambial. Os governos de Fernando Henrique Cardoso e Luiz Inácio da Silva, procurando solucionar o problema, recorreram aos empréstimos do Fundo Monetário Internacional (FMI) em três sucessivas operações de socorro, em 1999, 2001 e 2003. Além dessa medida, alterou-se, a partir do segundo mandato de FHC, a política econômica para buscar gerar saldos através do comércio exterior, com o intuito de suprir o déficit da Conta Corrente. Neste contexto de crise econômica, os setores primário-exportadores foram escalados para gerar este saldo comercial. Deste modo, a agricultura capitalista, que passou a ser denominada de agronegócio, voltou às prioridades da agenda política macroeconômica externa e da política agrícola interna (DELGADO, 2012: 93). 
O agronegócio se constitui através de um pacto entre o grande capital agroindustrial, a grande propriedade fundiária e o Estado, cumprindo este último, um papel fundamental. Como ressalta Beatriz Heredia, Sérgio Leite e Moacir Palmeira (2010: 165), apesar das diversas definições conceituais existentes em torno do agronegócio, é possível constatar através da bibliografia especializada no assunto e das visitas realizadas pelos pesquisadores às áreas de campo "os enormes investimentos que põem em evidência o fato de que não se pode falar do agronegócio sem pensar no Estado e nas políticas públicas, que não só viabilizam a sua origem mas também sua expansão".

As políticas de investimento no agronegócio, que começaram no segundo mandato de FHC e se aprofundaram nos dois governos Lula e no governo de Dilma Rousseff, encontraram, sobretudo, entre 2000 e 2010, um comércio mundial muito favorável a algumas commodities (soja, miIho, açúcar-álcool, carnes bovinas e de aves, celulose de madeira), que juntamente com os produtos mineiras, passaram a dominar a pauta das exportações brasileiras (DELGADO, 2012: 95). O grande sucesso desta opção primário-exportadora coube ao governo Lula no período de 2003/07, quando expressivos saldos comerciais, oriundos destas exportações, superaram o déficit de serviços da Conta Corrente.

Esse pacto fez com que os grandes proprietários rurais e as grandes empresas com investimentos nas cadeias agroindustriais se tornassem uma base importante de sustentação político-econômica de todos os governos federais a partir do segundo mandato de FHC, mais especificamente do ano 2000 , gerando um reflexo imediato na luta pela reforma agrária. O princípio da função social foi ignorado por estes governos. As diferentes ações que foram empregadas por eles para construir a hegemonia do agronegócio se colocaram antagonicamente às políticas que buscavam implementar uma reforma agrária distributivista. A recusa em atender as reivindicações de democratização do acesso à terra através de repertórios como as ocupações de grandes propriedades rurais foi uma das iniciativas mais explícitas a favor do agronegócio.

Se FHC estava disposto a desapropriar e redistribuir terras até o final dos anos 1990, nos anos 2000 isso mudou completamente. Em 
seu primeiro mandato e início do segundo, ele apostou que conseguiria amenizar os conflitos por terra através de uma ampla política de assentamentos - inclusive para enfraquecer organizações como o MST. O objetivo, portanto, era assentar 40 mil famílias em 1995, 60 mil em 1996, 80 mil em 1997 e 100 mil em 1998, totalizando, ao final de quatro anos, 280 mil famílias (COMPARATO, 2001: 107-108). A ideia era a de desmobilizar a massa de indivíduos que estavam sendo mobilizadas pelas organizações por meio do atendimento de suas demandas. Mas as autoridades do governo não esperavam que a política de criação de assentamentos rurais geraria mais demanda por terra, ao invés de diminuí-la. Nos períodos que houve uma política de criação de assentamentos, houve um aumento acentuado no número de ocupações (ver Gráfico 2).

Gráfico 2 - Brasil - Números de Ocupações e de Assentamentos - 1988-2012

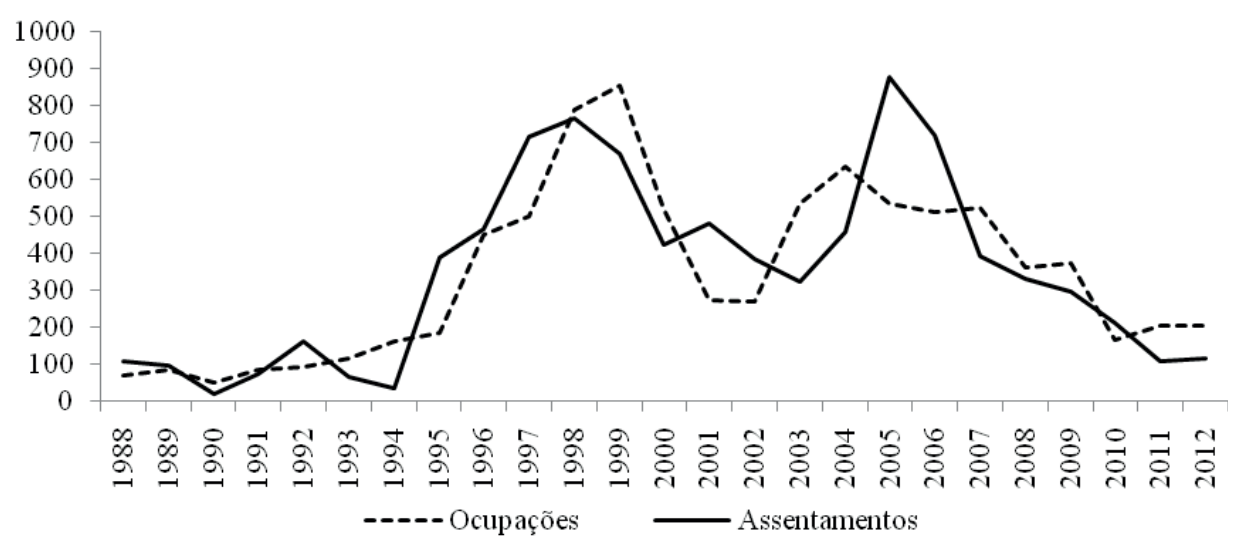

Fonte: Elaboração a partir dos dados do Banco de Dados da Luta pela Terra - DATALUTA

Desta maneira, no momento que o setor primário-exportador foi escalado para gerar o saldo comercial, o governo $\mathrm{FHC}$, percebendo a dinâmica das ocupações, passou a reprimi-las. As primeiras providências para combater as organizações que adotavam este repertório foram restringir as verbas públicas destinadas aos assentamentos rurais, abalando a eficácia das ocupações como meio de reivindicar a distribuição das terras e, ao mesmo tempo, incrementar as verbas des- 
tinadas à "reforma agrária de mercado"11 (COLETTI, 2005: 230). Além disso, houve um intenso processo de criminalização das organizações de luta pela reforma agrária e de repertórios como as ocupações. Uma das providências tomadas por FHC e mantida nos governos Lula e Dilma foi a promulgação da Medida Provisória 2109-52/2001, que proíbe a vistoria por dois anos dos imóveis ocupados (OLIVEIRA, 2001).

Os governos Lula investiram muito mais na regularização fundiária de terras de posseiros que já viviam na região amazônica do que na desapropriação de terras para a criação de novos assentamentos. Ou seja, o princípio da função social da terra também foi rechaçado pelos dois governos Lula. A opção política de não assentar por meio da desapropriação, mas, principalmente, através da regularização fundiária, gerou um problema para as organizações que mais atuavam utilizando-se das ocupações de terra. A predominância da criação de assentamentos através da regularização fundiária fez com que o tempo de acampamento das famílias que participavam das ocupações aumentasse consideravelmente. Sem conquistas, muitas famílias abandonaram os acampamentos, fazendo com que, provavelmente, outros indivíduos não se engajassem em novas ocupações (FERNANDES, 2008: 81).

Como afirmou João Paulo Rodrigues:

O que dificulta para o MST fazer luta e aumentar a base social acampada não é o programa social do governo, é a demora em sair terra. Desestimula não só quem está acampado, mas as pessoas em volta, primos, amigos, a família. Como eu vou acampar se não tem perspectiva nenhuma de sair terra? O que dificulta a mobilização, e nisso o governo acertou na mosca, é não desapropriar. Esse é o primeiro componente (RODRIGUES, 2014).

11 A chamada "reforma agrária de mercado" é implementada no Brasil através de três programas do governo federal, que contam com o financiamento do Banco Mundial. São eles: o Banco da Terra, a Cédula da Terra e o Programa de Combate à Pobreza Rural. O que há em comum entre estes três programas é que eles têm como principal objetivo financiar a compra de terras para trabalhadores rurais sem terras ou possuidores de terras insuficientes para prover o sustento da família. Deste modo, diferentemente das desapropriações por interesse social, a obtenção das terras se dá através da negociação meramente comercial entre os trabalhadores (comprador) e os grandes proprietários (vendedor). Para saber mais, ver Medeiros (2005) e Sabbato (2005). 
O governo Dilma foi o que menos assentou. Nos dois primeiros anos (2011 e 2012) foram criados 228 assentamentos, superando apenas os dois primeiros anos do governo Collor, quando foram criados 97 . Um dos motivos apontados pelo próprio governo para o pequeno volume de assentamentos foi, segundo a matéria da Carta Capital, o encarecimento da terra, cujo preço médio do hectare subiu, entre 2001 e 2011 , de $\mathrm{R} \$ 443,00$ para R \$ 1.967,00, sem considerar a inflação. Contando com a inflação medida pelo IGP-DI, mais sensível ao dólar, o valor subiu para R\$2.012 (BARROCAL, 2013).

A alta dos preços foi particularmente grande após a crise econômica de 2008, pois empresas estrangeiras, procurando fugir da crise, investiram em terras e empreendimentos agrícolas no país para aproveitar o aquecimento do mercado mundial de commodities. De acordo com estudos encomendados pelo Núcleo de Estudos Agrários e Desenvolvimento Rural (NEAD), do Ministério do Desenvolvimento Agrário (MDA), houve um crescimento significativo de investimentos estrangeiros diretos totais no Brasil a partir de $2002-107 \%$ no período de 2002 a 2008, passando de 4,33 para 8,98 bilhões de dólares (LEITE; SAUER, 2012: 511).

Importante lembrar que nos anos 1990 a terra se desvalorizou profundamente. Um estudo realizado pelo Centro de Estudos Agrícolas da Fundação Getúlio Vargas (FGV) mostrou que, no período de 1990 e 1999, o preço das terras de lavoura no Brasil registrou queda real (já descontada a inflação) de $50,3 \%$ e o preço das terras de pastagens $60,8 \%$. A desvalorização após o Plano Real foi maior ainda: 56,8\% no primeiro caso e 69\% no segundo (COLETTI, 2005: 164-165). Esta desvalorização levou o ministro da área agrária à época afirmar que a estrutura do latifúndio no Brasil estava finalmente quebrada (LEITE; SAUER, 2012: 516).

Sabe-se que o argumento utilizado pelo governo é razoável, visto que o aumento do preço da terra prejudica a execução das políticas fundiárias, pois, entre outros fatores, fica mais caro desapropriar e indenizar os imóveis rurais. Entretanto, parte significativa dos investimentos estrangeiros, que são um dos principais responsáveis pela alta do preço, foi financiada com recurso público, evidenciando 
a orientação do governo em favorecer os setores que compõem o pacto do agronegócio. Nos anos de 2007 e 2008, o Banco Nacional de Desenvolvimento Econômico e Social (BNDES) financiou mais de 50 projetos do setor sucroalcooleiro para a produção de etanol, sendo boa parte destinada à compra de equipamentos e à ampliação do parque industrial. Em outras palavras, os próprios governos têm contribuído, via financiamento de investimentos na produção de commodities, além de outras ações, para o aquecimento do mercado de terras, não sendo, portanto, um agente passivo neste arranjo (LEITE; SAUER, 2012: 515-516).

Todas as medidas que foram mencionadas acima, além de várias outras que também poderiam ser citadas, revelam como o pacto que conforma a hegemonia do agronegócio está relacionado à redução das ocupações de terra. $\mathrm{O}$ avanço deste modelo produtivo no campo brasileiro vai contra o princípio da função social e ambiental da terra e, por consequência, contra a realização de uma reforma agrária distributivista. Assim, a ocupação, que era o principal repertório empregado para reivindicar a desapropriação e redistribuição da terra, passou a ser ineficaz sobre um ambiente de intensa ameaça e repressão.

\subsection{O ENFRAQUECIMENTO DO APOIO À BANDEIRA DA REFORMA AGRÁRIA}

Após o Massacre, que ocorreu no ano de 1996, em Eldorado dos Carajás-PA, o MST organizou, em 1997, a chamada Marcha a Brasília, que, segundo Stédile, tinha como principal objetivo promover um diálogo com a população durante o trajeto. A Marcha foi formada por três colunas que saíram do Sudeste, do Centro-Oeste e do Sul, caminhando, cada uma delas, por mil quilômetros até Brasília, onde foi realizada uma imensa manifestação com a participação, não apenas dos integrantes do MST, mas de diversos atores que eram contra as políticas neoliberais que estavam sendo implementadas pelo governo federal (FERNANDES; STÉDILE, 1999: 152). A Igreja Católica foi fundamental durante todo processo, cedendo igrejas e casas paroquiais para os participantes passarem as noites e contribuindo com a arreca- 
dação de alimentos e dinheiro (COMPARATO, 2001: 114). A partir da Marcha, o MST se lançou como um dos principais atores políticos no cenário brasileiro e conseguiu popularizar ainda mais a bandeira da reforma agrária a nível nacional.

Uma pesquisa realizada pelo Instituto Brasileiro de Opinião Pública e Estatística (IBOPE) nesta época confirmou que $80 \%$ dos 3.000 entrevistados eram favoráveis às redistribuições de terras improdutivas, enquanto que apenas $12 \%$ se posicionavam contra, demonstrando que grande parte da população concordava com a realização de uma reforma agrária distributivista. Enquanto a aceitação era maior no Nordeste (86\%), a rejeição era maior no Sul do país (15\%). Entretanto, quando os entrevistados foram questionados em relação às ocupações de terra, as opiniões se dividiram: 59\% desaprovavam as ações e 34\% aprovavam. Este resultado indica que, mesmo apoiando uma reforma agrária distributivista, a maioria da população não achava a ocupação um meio legítimo de reivindicá-la (IBOPE, 1998). Segundo Bruno Comparato, durante a Marcha, a popularidade do MST atingiu seu auge, chegando à marca de $77 \%$ de apoio (COMPARATO, 2001: 116).

No entanto, quase uma década depois, outra pesquisa também realizada pelo IBOPE, em 2006, apontava mudanças na opinião da população brasileira, principalmente no que diz respeito ao MST e às ocupações de terra. Perguntados se as ações do MST traziam mais resultados positivos ou negativos para as negociações da reforma agrária, $56 \%$ dos 2.002 entrevistados responderam que trazia mais resultados negativos, enquanto $32 \%$ responderam que trazia mais resultados positivos. Os entrevistados também foram questionados se as ocupações abalavam a democracia brasileira. $76 \%$ afirmaram que abalava e apenas $16 \%$ disseram que não. A não ser que grande parte dos entrevistados compreendesse o "abalo da democracia brasileira" como algo positivo, é possível interpretar que a maioria não aprovava as ocupações de terra. Interpretação que pode ser corroborada com base na resposta dos $53 \%$ dos entrevistados que acreditavam que o governo deveria utilizar a polícia para retirar os integrantes do MST das propriedades ocupadas (IBOPE, 2006). 
Em maio de 2008, outra pesquisa feita pelo IBOPE também apontou resultados distintos das pesquisas levadas a cabo no final da década de 1990. Dos 2.100 entrevistados em várias partes do Brasil, $97 \%$ disse conhecer - bem (22\%) ou pouco (75\%) - o MST. Entre aqueles que disseram conhecê-lo, $50 \%$ se mostrou desfavorável (36\% "desfavorável" e 14\% "muito desfavorável") e 46\% manifestou ser favorável (38\% "favorável" e $8 \%$ "muito favorável") ao Movimento. Perguntados quais palavras de uma lista fechada descreviam melhor o MST, a maioria dos entrevistados respondeu "violência", demonstrando estar em conformidade com o teor do discurso midiático dos grandes meios de comunicação sobre o Movimento. É razoável supor que o fato de parte considerável da população relacionar o MST à violência está ligado à falta de legitimidade que a ocupação de terra passou a possuir (IBOPE, 2008).

As igrejas católicas e evangélicas, que apoiaram de diferentes formas as organizações de luta pela reforma agrária (FERNANDES, 2001), também deixaram de apoiar com o mesmo afinco as mobilizações em defesa da democratização da terra. Desde a década de 1980, grupos de cristãos contrários às ideias e às práticas preconizadas pela Teologia da Libertação vinham ganhando força dentro de suas igrejas. Com o crescimento do movimento denominado carismático, entre os católicos, e das igrejas neopentecostais, entre os evangélicos, o "neoconservadorismo" cristão passou imperar nestas instituições religiosas. Na Igreja Católica, o movimento carismático atingiu seu auge com a nomeação do Cardeal Ratzinger para assumir o lugar do papa João Paulo II, em 2005, quando passou a ser chamado de Bento XVI. Ratzinger, que deixou o posto de papa em fevereiro de 2013, sempre foi conhecido por ser um dos principais teólogos do Vaticano engajados em combater a Teologia da Libertação, cujos princípios, segundo ele, não passam de uma "heresia marxista".

De acordo com Antonio Menezes Neto:

No novo século, observa-se que a presença da Igreja Católica nos assentamentos é mais restrita às missas e celebrações do que propriamente às ações políticas [...] As lideranças e os as- 
sentados mais engajados nas lutas do MST reconhecem que apenas uma pequena parcela da Igreja Católica e das igrejas evangélicas expressa solidariedade com as lutas políticas do Movimento. No caso da Igreja Católica, tem-se também a dependência hierárquica de padres politicamente comprometidos com os movimentos populares às Dioceses e aos bispos que, em momentos de retração popular e conservadorismo político, travam a atuação política (MENEZES NETO, 2007: 340).

Interessante notar que no período em que os grupos ligados às igrejas católicas e evangélicas dedicavam um forte apoio às mobilizações em defesa da reforma agrária distributivista houve um aumento considerável das ocupações de terra. Do mesmo modo, no período em que parte considerável da população dizia ser favorável à bandeira da reforma agrária, que o MST contava com $77 \%$ de apoio e que uma quantidade razoável de pessoas, apesar de minoritária, dizia apoiar as ocupações de terra, houve uma intensificação no emprego deste repertório de ação. Portanto, provavelmente, a partir do momento que estas situações se inverteram, isto é, a partir do momento que houve o aumento da taxa de rejeição às ocupações e que o MST deixou de contar com o mesmo apoio que recebia das instituições cristãs e da própria população, tornou-se muito mais custoso realizar mobilizações em defesa da profunda transformação da estrutura fundiária brasileira, gerando, com isso, um arrefecimento no emprego das ocupações de terra no Brasil.

\subsection{A DIMINUIÇÃO DE INDIVÍDUOS EM SITUAÇÃO DE PENÚRIA}

O aumento da pobreza está diretamente vinculado às ocupações de terras, na medida em que gera um contingente de pessoas dispostas a se engajar e se arriscar num conflito para tentar "melhorar de vida". Não é à toa que a situação de penúria causada, muitas vezes, pelo desemprego e pela expropriação dos camponeses de suas terras aparece em estudos como uma condição social que incentiva os indivíduos a participarem das ocupações. NashieliLoera apontou, com base 
em informações colhidas no campo, como a situação de penúria era uma condição fundamental para gerar este engajamento. Num dos depoimentos, uma dos indivíduos que estava acampada afirmou que foi "pegar terra por causa da necessidade, da fome" (LOREA, 2006: 40); em outro, um dos acampados afirmou que o fato de estar no acampamento para "ganhar terra" representava uma forma de não precisar pedir mais nada para os seus filhos e uma alternativa ao desemprego (LOERA, 2006: 48).

Tirando aqueles que só admitem reproduzir suas vidas como trabalhadores rurais e os que se engajam nas ocupações por serem militantes, é difícil - mas não impossível - pensar que os indivíduos se proporiam a enfrentar todas as dificuldades de um acampamento contando com boas ofertas de empregos. Como assinala Luiz Gaiger (1999: 86-87), um dos principais motivos para os indivíduos aderirem às mobilizações do MST é o de conceberem o conflito como a melhor forma para resolver seus problemas materiais. Portanto, quando se tem um canal de melhoria material aberto, o conflito deixa de ser a alternativa mais interessante.

Neste sentido, vale notar que no mesmo período que o número de ocupações atingiu as suas maiores marcas, isto é, na década de 1990, o nível de desemprego no Brasil bateu seu recorde histórico. Tomando como referência a Pesquisa de Emprego e Desemprego (PED) realizada pelo DIEESE e pela SEADE para região metropolitana de São Paulo, a taxa de "desemprego total"12 passou de 8,7\%, em 1989, para $19,3 \%$, em 1999. Com base na mesma pesquisa, na região metropolitana do Rio Grande do Sul não foi diferente. Em 1993, a taxa era de

12 O desemprego total é a soma do desemprego aberto, que refere-se àquele trabalhador que não trabalhou na semana anterior à pesquisa, mas que procurou trabalho nos trinta dias anteriores, com o desemprego oculto, que podem ser o desemprego oculto pelo trabalho precário - referente às pessoas desempregadas que procuram emprego, mas que não entram na taxa de desemprego aberto porque desempenharam algum tipo de atividade descontinua e irregular na semana anterior à pesquisa - ou o desemprego oculto pelo desalento - referente aos desempregados que não trabalharam na semana anterior e que, por desânimo, não buscaram emprego nos trinta dias anteriores à data da entrevista, embora o tivessem feito num período de até doze meses anteriores ao levantamento. 
12,2\% e, em 1999, era de 19\%. Em Minas Gerais também houve um aumento de 12,7\%, em 1996, para 17,9\%, em 1999.

Depois da crise cambial de 1999, os governos Lula e Dilma passaram a adotar uma política econômica, que se contrapunha, em alguns aspectos, às políticas de caráter neoliberal, responsáveis pelas elevadas taxas de desemprego ${ }^{13}$. Algumas das medidas que foram tomadas para mudar a política econômica fazem parte do pacto do agronegócio. Outras, como os volumosos investimentos no setor da construção civil e da indústria naval, contribuíram para geração de milhões de postos de emprego (ver Gráfico 3).

Gráfico 3 - Taxa de Desemprego nas Regiões Metropolitanas de SP, MG e RS.

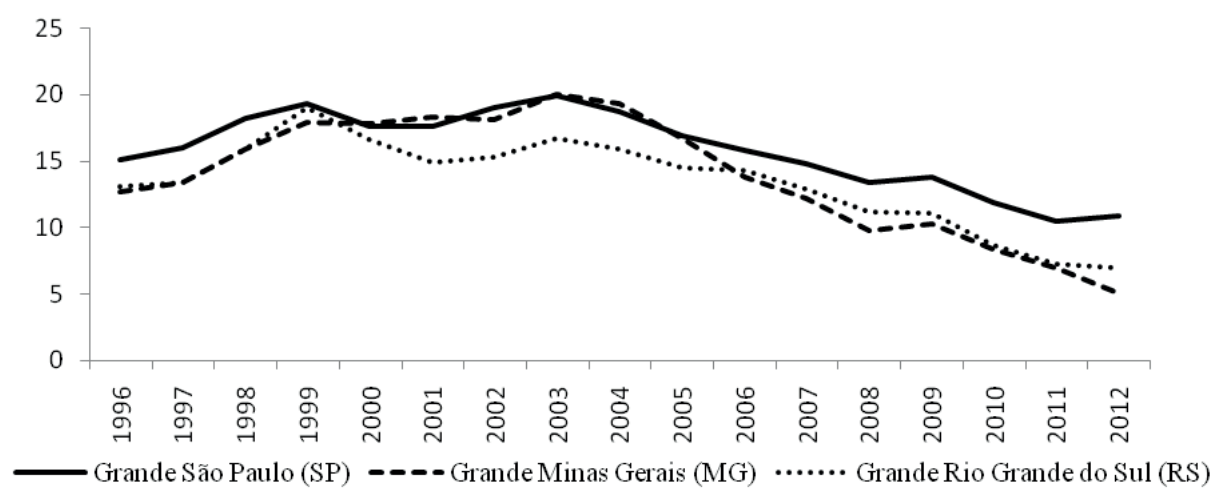

Fonte: Elaboração própria a partir dos dados de Pesquisa de Emprego e Desemprego do DIEESE/SEADE.

Portanto, a redução das taxas de desemprego teve algum impacto na redução das ocupações de terra. Interessante notar que a região metropolitana de São Paulo foi a que registrou a menor queda no nível do desemprego, comparada às outras duas regiões, e a que mais registrou ocupações de terra durante este período. De 2006 (ano que a taxa de desemprego da grande São Paulo se destacou das demais) a 2012, Minas Gerais respondeu por 188 ocupações, Rio Grande do Sul respondeu por 60 e São Paulo por 542. No período de 2004 a

13 Para mais informações sobre as mudanças político-econômicas adotadas nos anos 2000, ver Boito (2007). 
2009, quase $1 / 5$ das ocupações de todo o país foram realizadas no estado de São Paulo.

Porém, o nível de desemprego não é o único fator responsável por conformar uma situação de penúria da população, apesar de possuir uma importância considerável. Políticas sociais, como o programa Bolsa Família, também podem ter afetado a redução do número de ocupações de terra, como afirmam, inclusive, alguns autores (GIRARDI; PEREIRA; ROSSETO, 2013; FREITAS et. al., 2014; GIRARDI; VINHA, 2014; MOURA; VICTOR, 2012).

Outra questão importante de ser destacada é que o aumento do desemprego não gera automaticamente o aumento das ocupações. Lygia Sigaud notou que tomar exclusivamente esta condição para explicar o fenômeno da intensificação das ocupações é um sério equívoco, pois na Zona da Mata Pernambucana, por exemplo, sempre houve desempregados, pelo menos desde os anos 1960, mas as ocupações só começaram a ser recorrentes na década de 1990. Este argumento poderia ser estendido para todo Brasil. Antes, as demissões eram enfrentadas através de processos judiciais. Os dirigentes sindicais estimulavam os trabalhadores a entrar com processos na Justiça do Trabalho para solicitar o reconhecimento do tempo de trabalho sem a assinatura em carteira, de forma a tornar onerosa suas demissões. Porém, os efeitos desse repertório passaram a ser ruins para os trabalhadores, pois aqueles que conseguiam manter-se em seus empregos tinham suas condições de trabalho deterioradas pelo aumento da intensidade de trabalho, pela perda de algumas garantias de que dispunham, como o acesso à terra para a lavoura de subsistência, e pela alteração nas modalidades de pagamento, que passavam a ser quinzenal em vez de semanal, e em cheque em vez de dinheiro (SIGAUD, 2006: 35).

\section{CONCLUSÃO}

Este trabalho procurou oferecer algumas pistas para se compreender o fenômeno da redução do número de ocupações de terra no Brasil. A partir da análise dos diversos trabalhos que se debruçaram sobre casos específicos de ocupações, foi possível perceber que, nos perí- 
odos de intensificação deste repertório, existiam algumas condições sociais comuns que foram determinantes para o aumento do número de ocupações. As transformações que ocorreram a partir da década de 2000 no confronto político em torno da reforma agrária solaparam todas as condições apresentadas.

Estas condições sociais demonstram que a redução das ocupações de terra não pode ser explicada levando-se em consideração um único fator, mas deve ser compreendida em sua complexidade. Deste modo, é importante enfatizar que tais condições não esgotam as chaves explicativas do problema. Sem dúvida, existem outras que contribuem para explicar tal fenômeno, mas que não foram abordadas no artigo. Entretanto, esta ressalva não tira a relevância das condições sociais que foram tratadas.

Assim, sem organizações interessadas em ocupar terras, sem governos inclinados a atender as reivindicações, sem todo o apoio de aliados e sem uma massa de indivíduos dispostos a se engajar nas mobilizações para reivindicar a desapropriação e distribuição das grandes propriedades rurais, seria difícil não se reduzir o número de ocupações de terra no Brasil. No entanto, isso não significa, de maneira alguma, que a luta pela reforma agrária foi superada, que os conflitos fundiários do país foram resolvidos e que as ocupações não voltarão se intensificar.

\section{REFERÊNCIAS}

BARROCAL, André. No lugar da terra, financiamento. Carta Capital, São Paulo: 22-23, 6 fev. 2013.

BOITO Jr., Armando. Estado e burguesia no capitalismo neoliberal. Revista Sociologia Política, Curitiba, n. 28, jun. 2007: 57-73.

BORGES, Antonádia. O emprego na política e suas implicações teóricas para uma antropologia da política. Anuário Antropológico, Rio de Janeiro, Tempo Brasileiro, 2006: 91-125. 
BRINGEL, Breno. The MST Agenda for Emancipation: Interfaces Between National Politics and Global Contestation. In: CARDOSO, Adalberto; PIETERSE, Jan N. (Eds.) Development, inequality and emancipation in Brazil. London/New York: Routledge, 2014. p. 97-120.

COELHO, Douglas C. et. al.Conflitos entre ruralistas, camponeses e indígenas no Paraná. Boletim DATALUTA, Presidente Prudente, n. 72: 2-12, dez. 2013. Disponível em http://www2.fct.unesp.br/nera/boletimdataluta/boletim_dataluta_12_2013.pdf. Acesso em: 13 jan. 2015.

COLETTI, Claudinei. A trajetória política do MST: da crise da ditadura ao período neoliberal. 2005. 299 f. Tese (Doutorado em Ciência Política) - Instituto de Filosofia e Ciências Humanas, Universidade Estadual de Campinas, Campinas, 2005.

COMPARATO, Bruno Konder. A ação política do MST. São Paulo em Perspectiva, São Paulo, v. 15, n. 4, 2001: 105-118.

DELGADO, Guilherme. Do capital financeiro à economia do agronegócio: mudanças cíclicas em meio século (1965-2012). Porto Alegre: Editora da UFRGS, 2012.

FERNANDES, Bernardo M. A ocupação como forma de acesso à terra. In: Congresso Internacional da Associação de Estudos Latino-Americanos, 23, 2001, Washington-DC, Anais do XXIII Congresso Internacional da Associação de Estudos Latino-Americanos, 2001: 1-19. Disponível em http://lasa.international.pitt.edu/Lasa2001/FernandesBernardoPort.pdf. Acesso em: 2 jun. 2015.

. O MST e as reformas agrárias do Brasil. OSAL - Observatório Social de América Latina, ano IX, n. 24, out. de 2008: 73-85.

FERNANDES, Bernardo M.; STÉDILE, João P. Brava gente. A trajetória do MST e a luta pela terra no Brasil. São Paulo: Fundação Perseu Abramo, 1999.

FERREIRA, Juliana G. O. A luta agrorreformista da Associação Brasileira de Reforma Agrária (ABRA) - 1964-1974. 2013. Dissertação (Mestrado em Ciências Sociais em Desenvolvimento, Agricultura e 
Sociedade) - Instituto de Ciências Humanas e Sociais, CPDA, Universidade Federal Rural do Rio de Janeiro, Rio de Janeiro, 2013.

FREITAS, R. et. al. O contexto das lutas sociais do campo nas cidades: mapeamento das manifestações no período de 2000-2012. BoletimDATALUTA, Presidente Prudente, n. 77: 2-10, mai. 2014. Disponível em http://www2.fct.unesp.br/nera/boletimdataluta/boletim _ dataluta_5_2014.pdf. Acesso em: 13 jan. 2015.

GAIGER, Luiz Inácio. As condições socioculturais do engajamento no MST. Estudos Sociedade e Agricultura, Rio de Janeiro, n. 13, out. 1999: 70-92.

GIRARDI, E.; PEREIRA, L.; ROSSETTO, O. Ações de luta pela terra no estado do Mato Grosso em 2011. Boletim DATALUTA, Presidente Prudente, n. 64: 2-10, abr. 2013. Disponível em http://www2.fct.unesp. br/nera/boletimdataluta/boletim_dataluta_4_2013.pdf. Acesso em: 13 jan. 2015.

; VINHA, J. Conjuntura da luta pela terra no Brasil: balanço e perspectivas. Boletim DATALUTA, Presidente Prudente, n. 75: 2-7, mar. 2014. Disponível em http://www2.fct.unesp.br/nera/boletimdataluta/boletim_dataluta_3_2014.pdf. Acesso em: 13 jan. 2015.

HEREDIA, B.; LEITE, S. P.; PALMEIRA, Moacir. Sociedade e Economia do "Agronegócio" no Brasil. Revista Brasileira de Ciências Sociais, São Paulo, v. 25, n. 74, out. 2010: 159-176.

IBOPE - Instituto Brasileiro de Opinião Pública e Estatística. Reforma agrária conta com a simpatia dos brasileiros. mar. 1998. Disponível em http://www.ibope.com.br/pt-br/noticias/Paginas/Reforma\%20 agr\%C3\%A1ria\%20conta\%20com\%20a\%20simpatia\%20dos\%20brasileiros.aspx. Acesso em: 29 jan. 2015.

Instituto Brasileiro de Opinião Pública e Estatística (IBOPE). Pesquisa de Opinião Pública sobre a imagem do MST e do INCRA. São Paulo: IBOPE, fev. 2006. 57 p. Relatório técnico. Disponível em http:// 
www.ibope.com.br/pt-br/noticias/Documents/opp025_mst_fev06.pdf. Acesso em: 29 jan. 2015.

. Avaliação Movimentos: MPM. São Paulo: IBOPE, mai. 2008. 62 p. Relatório técnico. Disponível em http://www.ibope.com.br/pt-br/ conhecimento/relatoriospesquisas/Lists/ RelatoriosPesquisaEleitoral/ OPP\%20080474\%20-\%20MPM\%20-\%20imagem\%20movimentos\% 20sociais.pdf Acesso em: 29 jan. 2015.

JORNAL DOS TRABALHADORES SEM TERRA (JTST). Edições de 1981-2011. Irregular.

LEITE, Sérgio P.; SAUER, Sérgio. Expansão agrícola, preços e apropriação de terra por estrangeiros no Brasil. RESR, Piracicaba, v. 50, n. 3, jul./set. 2012: 503-524.

LOERA, NashieliR.A espiral das ocupações de terra. São Paulo: Polis; Campinas: CERES, 2006.

MACEDO, Marcelo. Entre a "violência" e a "espontaneidade": reflexões sobre os processos de mobilização para ocupações de terra no Rio de Janeiro. Mana, Rio de Janeiro, v. 11, n. 2, 2005: 473-497.

Sementes em trincheiras: estado do Rio de Janeiro (19481996). In: MACEDO, Marcelo; ROSA, Marcelo; SIGAUD, Lygia. Ocupações e acampamentos: sociogênese das mobilizações por reforma agrária no Brasil. Rio de Janeiro: Garamond, 2010. p. 133- 265.

MACEDO, Marcelo; ROSA, Marcelo; SIGAUD, Lygia. Ocupações de terra, acampamentos e demandas ao Estado: uma análise em perspectiva comparada. DADOS - Revista de Ciências Sociais, Rio de Janeiro, v. 51, n. 1, 2008: 107-142.

- Ocupações e acampamentos: estudo comparado sobre a sociogênese das mobilizações por reforma agrária no Brasil (Rio Grande do Sul, Rio de Janeiro e Pernambuco) 1960-2000. Rio de Janeiro: Garamond, 2010. 
MARTINS, José de Souza. A política do Brasil lúmpen e místico. São Paulo: Contexto, 2011.

MEDEIROS, Leonilde S. A questão da reforma agrária no Brasil 1955-1964. 1982. 150 f. Dissertação (Mestrado) - Faculdade de Filosofia, Letras e Ciências Humanas, Universidade de São Paulo, São Paulo, 1982.

. Banco da Terra. In: MOTTA, Márcia (org.) Dicionário da Terra. Rio de Janeiro: Civilização Brasileira, 2005. p. 49-51.

. História dos movimentos sociais no campo. Rio de Janeiro: FASE, 1989.

. Lavradores, trabalhadores agrícolas, camponeses: os comunistas e a constituição de classes no campo. 1995. 295 f. Tese (Doutorado em Ciências Sociais) - Instituto de Filosofia e Ciências Humanas, Universidade Estadual de Campinas, Campinas, 1995.

MENEZES NETO, Antonio. A Igreja Católica e os movimentos sociais do campo: a Teologia da Libertação e o Movimento dos Trabalhadores Rurais Sem Terra. Caderno CRH, Salvador, v. 20, n. 50, mai./ago. 2007: 331-341.

MOURA, Daise; VICTOR, Fabiana. Ocupações e manifestações em Minas Gerais: a luta pela terra a partir da pesquisa DATALUTA, 19902010. In: Encontro Nacional de Geografia Agrária, 21, 2012, Uberlândia-MG, Anais do XXI Encontro Nacional de Geografia Agrária, Uberlândia-MG, Universidade Federal de Uberlândia, 2012: 1-12.

Movimento dos Trabalhadores Rurais Sem Terra (MST). Nossa proposta de Reforma Agrária Popular. jul. 2009. Disponível em antigo. www.mst.org.br/node/7708. Acesso em: 15 jan. 2015.

OLIVEIRA, Ariovaldo Umberlino de. A longa marcha do campesinato brasileiro: movimentos sociais, conflitos e reforma agrária. Estudos Avançados, São Paulo, v. 15, n. 43, 2001: 185-206. 
PALMEIRA, Moacir. Modernização, Estado e questão agrária. Estudos Avançados, São Paulo, v. 3, n.7, set./dez. 1989: 87-108.

RODRIGUES, João Paulo. MST 30 anos: "Estamos no canto do ringue”. Repórter Brasil, Brasília, fev. 2014. Entrevista concedida a Daniel Santini. Disponível em http://reporterbrasil.org.br/2014/02/mst-30-anos-estamos-no-canto-do-ringue/\#partell. Acesso em: 29 jan. 2014.

ROSA, Marcelo. As novas faces do sindicalismo rural brasileiro: a reforma agrária e as tradições sindicais na Zona da Mata de Pernambuco. DADOS - Revista de Ciências Sociais, Rio de Janeiro, v. 47, n. 3, 2004: 473-503.

- Encruzilhadas: acampamentos e ocupações na Fazenda Sarandi, Rio Grande do Sul (1962-1980). In: MACEDO, Marcelo; ROSA, Marcelo; SIGAUD, Lygia. Ocupações e acampamentos: sociogênese das mobilizações por reforma agrária no Brasil. Rio de Janeiro: Garamond, 2010. p. 19-131.

SABBATO, Alberto Di. Cédula da Terra. In: MOTTA, Márcia (org.) Dicionário da Terra. Rio de Janeiro: Civilização Brasileira, 2005. p. 91-93.

SIGAUD, Lygia. A forma acampamento: notas a partir da versão pernambucana. Novos Estudos CEBRAP, São Paulo, n. 58, nov. 2000: 73-92.

. Ocupações de terra, Estado e movimentos sociais no Brasil. Cuadernos de Antropología, Social, Buenos Aires, n. 20, 2004: 11-23.

SIGAUD, Lygia et al. Os acampamentos da reforma agrária: história de uma surpresa. In: L'ESTOILE, Benoît; SIGAUD, Lygia (org.). Ocupações de terra e transformações sociais. Rio de Janeiro: Editora FGV, 2006. p. 29- 63.

SILVA, Diógenes Luiz da.Do latifúndio ao agronegócio: os adversários do MST no Jornal Sem Terra. 2013. 171 f. Dissertação (Mestrado em Ciências Sociais em Desenvolvimento, Agricultura e Sociedade) - Instituto de Ciências Humanas e Sociais, CPDA, Universidade Federal Rural do Rio de Janeiro, Rio de Janeiro, 2013. 
STÉDILE, João P. "Está em curso, no Brasil, uma concentração da propriedade da terra”. IHU On-Line, São Leopoldo, mai. 2014a. Entrevista concedida a PatriciaFachin e Luciano Gallas. Disponível em http:// www.ihu.unisinos.br/entrevistas/531351-as-eleicoes-presidenciais-nao-tem-como-proposito-recolocar-a-questao-da-reforma-agraria-entrevista-especial-com-joao-pedro-stedile-. Acesso em: 4 jan. 2015.

. MST, 30. Muito além da distribuição de terras. Revista Fórum, jan. 2014b. Entrevista concedida a Igor Carvalho e Glauco Faria. Disponível em http://revistaforum.com.br/digital/131/mst-30-muito-alem-da-distribuicao-de-terras/. Acessoem: 29 jan. 2015.

TARROW, Sidney.Power in Movement.Social Movements and contentious politics. $3^{\mathrm{a}}$ ed. Cambridge: Cambridge University Press, 2011.

TEIXEIRA, Gerson. Reforma Agrária assume dimensão estratégica. IHU On-Line, fev. 2014. Entrevista concedida a Luciano Gallas e Patrícia Fachin. Disponível em antigo.mst.org.br/node/15732. Acesso em: 29 jan. 2015.

TILLY, Charles. From Mobilization to Revolution. Boston: Wesley Publishing Co., 1978.

. Regimes and Repertoires.Chicago: Chicago University Press, 2006.

TL - TERRA LIVRE. Edições de 1949-1964. Irregular.

ZÉ PUREZA. Direção de Marcelo Ernandez Macedo. Rio de Janeiro, 2006 (97 min.). Disponível em https://www.youtube.com/ watch?v=EH4Uf9dSLTw. Acesso em 29 jan. 2015 